\title{
Disease and Diagnosis
}

\section{Effect of Aromatherapy with Lavender on Labor Pain: A Literature Review}

\author{
Razieh Hatami Rad $^{*}(\mathbb{D})$ \\ Department of Midwifery, Ahvaz Branch, Islamic Azad University, Ahvaz, Iran.
}

\begin{abstract}
Background: Controlling labor pains is now an essential part of midwifery care, and aromatherapy is a well-known medicinal treatment for easing labor pains. The aim of this research was to evaluate and analyze the most recent clinical trial results on the effects of lavender aromatherapy on labor pain management.

Methods: Several keywords were searched in the MEDLINE/PubMed, Scopus, and Google Scholar databases, including lavender, Lavandula, childbirth, labor, pregnancy, labor pain, aromatherapy, and delivery. Two authors extracted the data, and the Cochran quality management tool was used to assess the consistency of each study.

Results: In general, 7 studies were reviewed after checking the titles and abstracts of the studies and eliminating obsolete or low-quality studies. Two studies were conducted in Egypt and Indonesia, and five studies were conducted in Iran. There were a wide variety of qualities in the studies, which could render more quantitative synthesis impractical. Massage aromatherapy was employed in three trials, and inhalation was applied in four studies. All findings suggested that lavender aromatherapy in both methods could reduce active phase labor pain.

Conclusion: Although the results of this study showed that lavender aromatherapy suppressed labor pain, more detailed randomized clinical trials with higher precision are needed to achieve an accurate outcome for data generalization regarding the use of labor pain management.

Keywords: Aromatherapy, Lavender, Labor Pain, Non-pharmacological, Clinical trial
\end{abstract}

\section{*Correspondence to}

Razieh Hatami Rad, Department of Midwifery, Ahvaz Branch, Islamic Azad University, Ahvaz, Iran. Tel: +986133348351, Email: Razieh-hatamirad@ iauahvaz.ac.ir

\section{Introduction}

Labor pain is one of the most extreme types of pain faced by nearly all females during labor (1) and may have negative consequences on both the mother and the fetus (2). Fear of labor pain, especially in nulliparous women, can influence mothers' choices for the next delivery process, leading to an increase in the mother's ability to have a selective cesarean section in the future $(3,4)$. Therefore, strategies for mitigating labor pain are critical, and both pharmacological and non-pharmacological approaches should be considered in the hopes of lowering the cesarean section rate $(5,6)$. Although some drugs have been shown to be helpful in mitigating labor pain, a Cochrane review study revealed that some treatments can reduce labor pain while still causing negative maternal and neonatal outcomes (7). The non-pharmacological methods of reducing labor pain are not intrusive although they are responsive and inexpensive and tend to be safe for both the mother and the fetus. However, the clinical effectiveness of these new methods has remained a source of debate due to the lack of credible data $(7,8)$. There are many other factors and labor methods and medications
(9-11) that might also affect the perception of pain or biochemical factors related to the mother's body (12).

According to numerous reports, non-pharmacological treatments such as water immersion, exercise classes, rehabilitation, heat and cold therapy, acupuncture, aromatherapy, massage, and music therapy have benefits such as excellent pain relief and warmth (1, 13-15).

Aromatherapy has been one of the non-pharmaceutical alternatives for easing labor pain. Aromatherapy is a term that describes a group of conventional, alternative, and complementary treatments that make use of essential oils (EOs) and other aromatic plant compounds. EOs, which have been used to enhance a person's health or disposition for over 6000 years, are plant extracts that are obtained by steaming or pressing various plant components (i.e., barks, fruits, and the leaves or flowers). Aromatherapy is characterized as a "treatment program or use of aromatic substances (EOs) for comprehensive treatment" by the National Association for Comprehensive Aromatherapy. Although aromatherapy has gained extensive interest in recent years, it still requires further investigation (13, 16). Based on preliminary studies, aromatherapy has the

(C) 2021 The Author(s). This is an open access article distributed under the terms of the Creative Commons Attribution License (http:// creativecommons.org/licenses/by/4.0/), which permits unrestricted use, distribution, and reproduction in any medium, provided the original work is properly cited. 
potential to alter brain frequencies (17-21). It also reduces depression by increasing cortisol, the "stress hormone", and thereby a feeling of well-being (22-25). According to some researchers, different scents have various effects on a wide variety of persons. Aromatherapy is a supplemental drug that cannot be used to cure medical problems on its own $(26,27)$. Various studies showed that aromatherapy can help with nausea and vomiting, body aches and pains, anxiety, confusion, stress and depression, exhaustion and insomnia, muscle aches, headaches, circulatory complications, menstrual problems, and menopausal symptoms among other things (25-29).

Lavender (Lavandula angustifolia), as a green mint family species, is one of the medicinal herbs that is applied in aromatherapy (30). The ketones in lavender are helpful in reducing pain and inflammation. Esters also avoid muscle spasms, relieving stress and depression (31).

Lavender aromatherapy was applied during labor and demonstrated positive effects in terms of pain relief and anxiety reduction (31-35). Based on previous evidence, those certain non-pharmacological methods (e.g., lavender aromatherapy) may improve labor outcomes although there is a need for a systematic look at the findings of published studies in this field. However, it has not been thoroughly explained, and there is no scientific consensus about the use of lavender aromatherapy in hospitals for suppressing labor pain. In fact, a lack of the analysis of related studies is one of the most important obstacles to the widespread use of lavender aromatherapy in clinical settings. Accordingly, the current review analysis was performed aiming at reviewing and summarizing the available data from clinical trials on the benefits of lavender aromatherapy on labor pain management.

\section{Methods}

A scientific search was performed using a variety of keywords such as aromatherapy, lavender, Lavandula, gestation, conception, labor, delivery, birth, and labor pain in internal and external databases such as MEDLINE/ PubMed, Scopus, and Google Scholar. Both related papers were included regardless of the publication year. Clinical trials investigating the efficacy of lavender as an aromatherapy agent for labor pain met the inclusion criterion. Studies using the other techniques of research design or having no access to the full text were excluded from the review. In addition, studies with insufficient data were not included in the study (Figure 1).

The reference lists of the compiled papers were searched
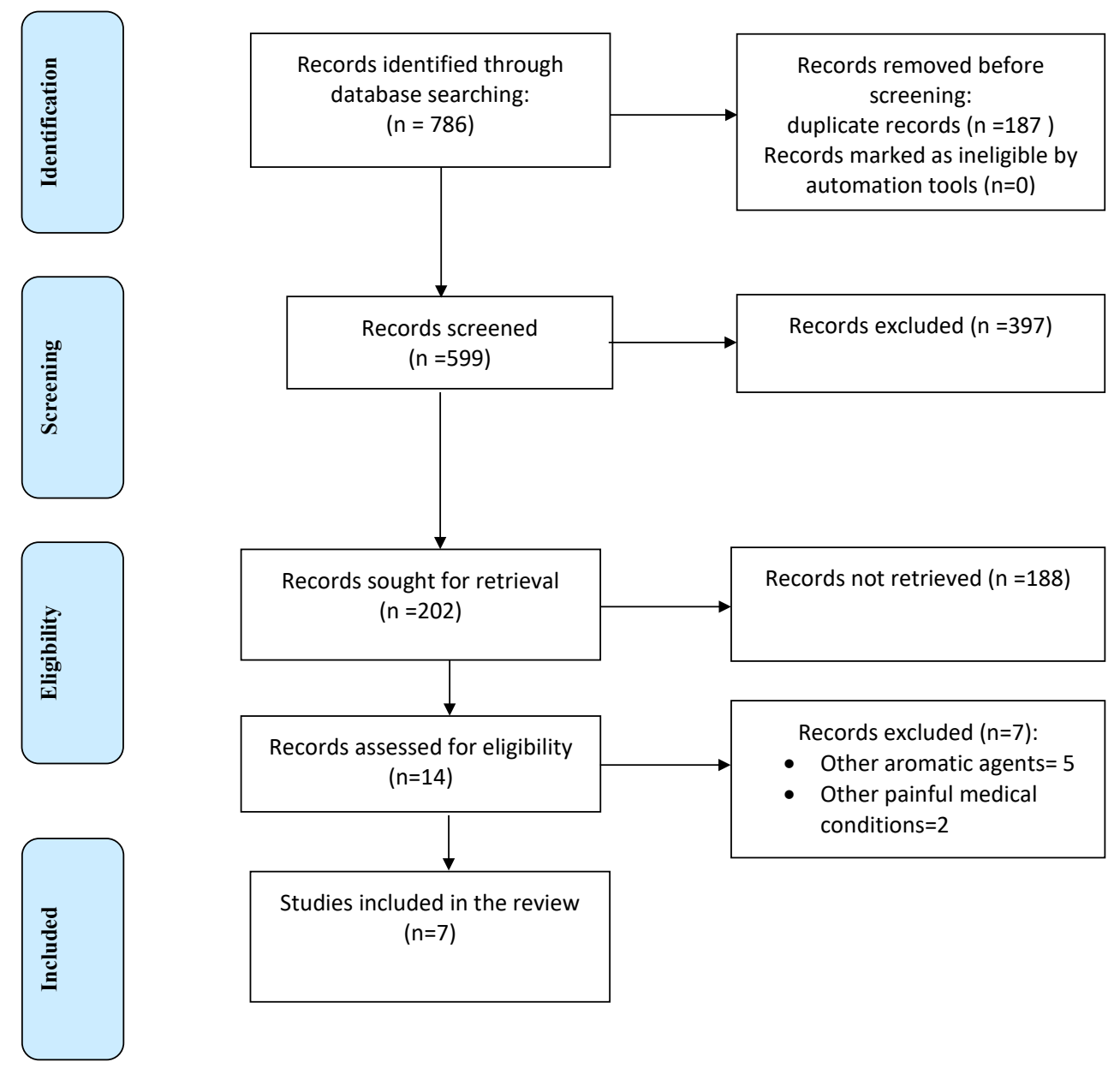

Figure 1. PRISMA Flow Chart. 
to find if there were any other important records. Personal correspondence was made with the authors of the papers when requiring more information. The research included experiments where the experimental setup was a clinical trial, and lavender aromatherapy was used to relieve labor pain at each stage of labor. Labor pain was measured using a $10 \mathrm{~cm}$ visualized grading scale as a research endpoint.

Irrelevant documents were initially omitted based on a screening of the titles and abstracts of the papers. The full texts of the papers that seemed to be significant were then further collected and analyzed to determine if they met the inclusion criterion. A form was created to collect data such as the research ID (the first author's name and publication year), region, aromatherapy style, outcomes, and the number of assessed pregnancies. The quality of the study was examined in terms of random allocation generation, random allocation concealing, blinding of participation and administrators, blindness in the evaluation of outcomes, incomplete outcome, selected finding presentation, and other potential biases.

\section{Results}

Seven studies were reviewed after querying the study titles and their abstracts and deleting elements that were obsoletes or of poor quality. Table 1 provides the properties of qualitative synthesis research.

Two studies focused on patients who had prior pregnancy experience $(23,36)$ while four studies by Kaviani et al $(37)$,

Table 1. Characteristics of the Final Reviewed Studies in the Present study

\begin{tabular}{|c|c|c|c|}
\hline First Author & Participants & Intervention & Outcome \\
\hline Abbaspoor (22) & $\begin{array}{l}\text { Sixty pregnant women (nulliparous and } \\
\text { multiparous) with a singleton embryo, } \\
\text { gestational period of }>36 \text { weeks, cephalic } \\
\text { appearance, cervical dilatation of } 4 \mathrm{~cm} \text { or } \\
\text { more, and three uterine contractions in } 10 \\
\text { minutes }\end{array}$ & $\begin{array}{l}\text { Intervention group }(\mathrm{n}=30) \text { : massage } \\
\text { and aromatherapy with two drops of } \\
\text { the EO in } 50 \mathrm{cc} \text { almond oil } \\
\text { - } \quad \text { Control group }(\mathrm{n}=30) \text { : } \\
\text { - Massage therapy }\end{array}$ & $\begin{array}{l}\text { The overall labor discomfort of both } \\
\text { groups considerably decreased after } \\
\text { the intervention. The intervention } \\
\text { group experienced a higher decline } \\
\text { in discomfort compared to the control } \\
\text { group. }\end{array}$ \\
\hline Kaviani (37) & $\begin{array}{l}\text { One hundred sixty primiparous women with } \\
\text { a gestational age of } 36 \text { weeks and a cervical } \\
\text { dilation of } 3-4 \mathrm{~cm} \text {. }\end{array}$ & $\begin{array}{l}\text { Intervention group }(\mathrm{n}=80) \text { : } \\
\text { Aromatherapy vaporization using } \\
\text { a handkerchief soaked in } 0.1 \mathrm{~mL} \\
\text { EOs in } 1 \mathrm{~mL} \text { saline solution and } \\
\text { connected to the collar } \\
\text { Control group }(\mathrm{n}=80) \text { : Handkerchief } \\
\text { soaked in } 2 \mathrm{~mL} \text { of saline solution } \\
\text { connected to the collar. }\end{array}$ & $\begin{array}{l}\text { The mean pain labor in the aromatherapy } \\
\text { group decreased } 30 \text { minutes and one } \\
\text { hour after the intervention. }\end{array}$ \\
\hline
\end{tabular}

The overall mean of the measured labor

Ninety Iranian multiparous pregnant women were aged $18-35$ years, with a single fetus,

Mohammadkhani (36) gestational age of 37-42 weeks, cervical dilatation of $4 \mathrm{~cm}$, gestation with minimal risk, and a moderate body mass index.
Intervention group I ( $\mathrm{n}=30)$ : EO back massage aromatherapy Intervention group II $(\mathrm{n}=30)$ : back massage with almond oil Back massage alone $(n=30)$ in the control group

ree times in each group showed that the pain was significantly less after the intervention in all groups compared to before the intervention. The most significant difference was related to the massage aromatherapy group with the lavender oil.

The overall mean of labor pain in the three measures did not vary significantly

There was no history of acute or chronic illness, no history of acute or chronic discomfort, and no allergy history in 120 multiparous women with a single fetus. p

Intervention group $(\mathrm{n}=60)$ : Cold incense guided with the lavender oil between the two groups ( $P=0.27)$. The Control group $(n=51)$ : Incense with cold water

difference in the mean pain between the two groups before and after the intervention was substantial $(P=0.03)$.

Intervention group $(\mathrm{n}=60)$ : Two drops of the lavender EO as inhalation aromatherapy in three stages (dilatations of 4,6 , and $8 \mathrm{~cm}$ ) Control group $(n=59)$ : Placebo (distilled water)

Intervention group $(\mathrm{n}=30)$ : Massage of the back with two drops of the EO in almond Control group ( $n=30)$ : Only massage

Intervention group $(\mathrm{n}=20)$ : Lavende oil in $10 \mathrm{~mL}$ packages as inhalation aromatherapy for 30 minutes Control group $(n=20)$ : No intervention
The difference in labor pain was significant before and after the intervention in the two groups $(P=0.001)$.

The lavender group experienced considerably less labor pain throughout the active and transitional phases compared to the control group.

When compared to the control group, the intervention group had a substantial reduction in labor discomfort. 
Lamadah and Nomani (38), Yazdkhasti and Pirak (39), and Karo et al (40) only evaluated nulliparous births. One paper delved into all types of births (18). A total of 37, 33, and 5 studies were undertaken in Indonesia, Egypt, and Iran, respectively $(22,36,37,39,41)$. Aromatherapy was used as massage aromatherapy in studies Lamadah and Nomani (38), Abbaspoor and Mohammadkhani Shahri (22), and Mohamadkhani Shahri et al (36), and inhaled aromatherapy with lavender was applied in four other studies $(37,39,40)$. The data relating to the reviewed studies are presented in Table 1. Massage aromatherapy treatments employed two separate arms of intervention, including massage therapy solely or massage with the EO of almond. Aromatherapy interventions used cold water fumigation, electric fumigation apparatus, and water-soaked napkins as comparison interventions. The studies usually had intermediate to mixed consistency. In three trials, random assignment was found to be at a low-risk level $(18,36)$. Table 1 provided the findings relevant to the studies. In both trials, the overall severity of labor pain was measured using a $10-\mathrm{cm}$ visual grading system. In certain studies, labor pressure was measured at 4,6 , and $8 \mathrm{~cm}$ cervix dilatations $(22,36,23)$. In the study by Kaviani et al (37), the labor pain was measured and registered 30 and 60 minutes after the intervention. In trials where aromatherapy was employed in combination with massage, the overall levels of labor pain were considerably lower in the intervention group compared to pre-intervention although no differentiation was detected between the experimental and control groups $(22,36)$. In a study, lavender massage aromatherapy reduced mean labor discomfort in the productive and transitional phases of labor considerably more than the control group (38). In three experiments at varying cervical dilatation stages, the overall mean of labor pain was not statistically different in inhalation aromatherapy via masks in comparison with the controls. On the other hand, the experimental group demonstrated a lesser increase in mean pain before and after the session compared to the control group (23). In a trial by Kaviani et al, napkins soaked in EOs and tied around the waist of the patient were utilized for respiratory aromatherapy and it was found that patients receiving the intervention had less labor pressure 30 and 60 minutes after the intervention (37). Karo et al also reported that the average of labor pain was lower in the intervention group compared with the control group after 30 minutes of aromatherapy using an electric unit (40).

\section{Discussion}

Although the primary mechanism of action of lavender aromatherapy is unknown, according to an analysis of clinical trial results in our research, it can make women in labor experience less pain during labor. Based on previous research on the psychological and physiological benefits of EOs, aromatherapy controls human mood and reduces anxiety without altering physiological circumstances $(41,42)$. Similarly, Tabatabaeichehr and Mortazavi assessed the efficacy of aromatherapy in the treatment of labor pain (29). To the best of our knowledge, our study is the first one to focus on a single aromatic agent. Further analysis (e.g., network meta-analysis) is proposed due to the large number of aromatic agents used in different studies. There seems to be a connection between anxiety and increased labor pain during childbirth. Labor pain, followed by labor anticipation, triggers maternal anxiety during labor and increases catecholamine intake, causing pain by stimulating the autonomic and humoral nervous systems. Aromatherapy works by allowing EOs to absorb into the respiratory system, which can reduce cortisol production while increasing serotonin levels. According to Mirzaei et al (33), aromatherapy EOs relieve stress in postpartum women, reduces cortisol production from the adrenal glands, and enhances gastrointestinal serotonin production $(33,43)$. The linalool in lavender inhibits acetylcholine release and alters the function of ion channels at the neuromuscular junction. Linalyl acetate and linalool are considered as narcotic and sedative, respectively, and are consumed by skin massage in about 5 minutes, and their plasma concentration peaks in about 20 minutes $(44,45)$. Furthermore, some experts believe that the distraction of aromatherapy is a major factor in the reduction of labor discomfort. These techniques are used to amuse women when they are in labor in order to alleviate their discomfort (46). In cases of massage aromatherapy, it seems that the scent of lavender or the subsequent massage procedure induces less emphasis on the discomfort of childbirth. Many concerns are raised in this review study about the basic dimensions of clinical trials that address the need for further research and evaluation. In general, the clinical trial represented moderate to mixed efficiency. The remaining studies lacked sufficient knowledge about the testing methods. The subjects were not blinded in the majority of clinical trials.

Additionally, some other systematic reviews and meta-analysis studies applied different search strategies with various outcomes in comparison with our study. However, all these studies show the potential benefits of aromatherapy with lavender on labor pain relief (47-49). Makvandi et al also performed an interventional study with the same beneficial results (49).

\section{Conclusion}

Despite the difficulties described, our research findings demonstrated that using lavender aromatherapy relieves labor pain in laboring women. Aromatherapy is inexpensive and necessitates no extensive preparation. However, more randomized controlled clinical trials would be needed to arrive at a precise and comprehensive conclusion. 


\section{Conflict of Interest Disclosures}

None.

\section{Acknowledgment}

None.

\section{Ethical Statement}

Not applicable.

\section{Authors' Contributions}

RHR designed the study. RHR conducted all literature reviews and manuscript writing.

\section{Funding/Support}

None.

\section{Informed Consent}

Not applicable.

\section{References}

1. Yadollahi P, Khormaie F, Makvandi S, Soofi A, Ariashekouh A, Hashemifard T. The relationship between personality traits and labor pain intensity. Int J Community Based Nurs Midwifery. 2013;1(4):224-9.

2. Dong C, Hu L, Liang F, Zhang S. Effects of electroacupuncture on labor pain management. Arch Gynecol Obstet. 2015;291(3):531-6. doi: 10.1007/s00404-0143427-x.

3. Smith A, Laflamme E, Komanecky C. Pain management in labor. Am Fam Physician. 2021;103(6):355-64.

4. Klomp T, Witteveen $\mathrm{AB}$, de Jonge A, Hutton EK, LagroJanssen AL. A qualitative interview study into experiences of management of labor pain among women in midwifeled care in the Netherlands. J Psychosom Obstet Gynaecol. 2017;38(2):94-102. doi: 10.1080/0167482x.2016.1244522.

5. Feldman E. Labor, pain management, and acupuncture: a cochrane review. Integr Med Alert. 2020;23(9).

6. Cunningham FG, Leveno KJ, Bloom S, Hauth J, Rouse D, Spong C. Williams Obstetrics. 23rd ed. New York, NY: McGraw-Hill; 2009.

7. 7Jones L, Othman M, Dowswell T, Alfirevic Z, Gates S, Newburn M, et al. Pain management for women in labour: an overview of systematic reviews. Cochrane Database Syst Rev. 2012;2012(3):CD009234. doi: 10.1002/14651858. CD009234.pub2.

8. Forrester LT, Maayan N, Orrell M, Spector AE, Buchan LD, Soares-Weiser K. Aromatherapy for dementia. Cochrane Database Syst Rev. 2014(2):CD003150. doi: 10.1002/14651858.CD003150.pub2.

9. Ehsani P, Hatamirad R. Comparing the effect of umbilical cord milking versus vein oxytocin injection and normal saline injection, on third stage of labor. J Neyshabur Univ Med Sci. 2015,3(3):64-72. [Persian].

10. Atarod Z, Roohanizadeh H, Saberi M, Hashemi SA, Fazli M. Circulating levels of homocysteine, zinc, iron and copper in pregnant women with pre-eclampsia. HealthMED. 2012;6(10):3329-544.

11. Atarod Z, Talebi F, Hashemi SA, Kheradmand A. Comparison of vaginal misoprostol application versus curettage in treatment of early pregnancy failure: a randomization clinical trial study. Afr J Pharm Pharmacol. 2013;7(20):1339-42. doi: 10.5897/ajpp12.1292.

12. Isha S, Pradhan N, Sharma J. Factors influencing perception of labor pain among parturient women at Tribhuvan University Teaching Hospital. Nepal Journal of Obstetrics and Gynaecology. 2013;8(1): 26-30.

13. Valiani M, Shiran E, Kianpour M, Hasanpour M. Reviewing the effect of reflexology on the pain and certain features and outcomes of the labor on the primiparous women. Iran J Nurs Midwifery Res. 2010;15(Suppl 1):302-10.

14. Makvandi S, Latifnejad Roudsari R, Sadeghi R, Karimi L. Effect of birth ball on labor pain relief: a systematic review and meta-analysis. J Obstet Gynaecol Res. 2015;41(11):1679-86. doi: 10.1111/jog.12802.

15. Hajian S, Shariati M, Mirzaii Najmabadi K, Yunesian M, Ajami MS. The effect of the extended parallel process model of childbirth education for decreasing the rate of Caesarean section among Iranian women. Life Sci J. 2012;9(3):445-52.

16. Tang SK, Tse MY. Aromatherapy: does it help to relieve pain, depression, anxiety, and stress in communitydwelling older persons? Biomed Res Int. 2014;2014:430195. doi: 10.1155/2014/430195.

17. Smith CA, Collins CT, Crowther CA. Aromatherapy for pain management in labour. Cochrane Database Syst Rev. 2011(7):CD009215. doi: 10.1002/14651858.cd009215.

18. Rivard R, Crespin D, Finch M, Johnson J, Dusek J. Effectiveness of therapeutic massage in conjunction with aromatherapy for pain and anxiety relief of hospitalized patients. J Altern Complement Med. 2014;20(5):A125. doi: 10.1089/acm.2014.5333.abstract.

19. Hodge NS, McCarthy MS, Pierce RM. A prospective randomized study of the effectiveness of aromatherapy for relief of postoperative nausea and vomiting. J Perianesth Nurs. 2014;29(1):5-11. doi: 10.1016/j.jopan.2012.12.004.

20. Huntley A, Hunt R. Some patients experience relief from postoperative nausea with aromatherapy. Focus Altern Complement Ther. 2014;19(2):114-5. doi: 10.1111/ fct.12116.

21. Ovayolu O, Seviğ U, Ovayolu N, Sevinç A. The effect of aromatherapy and massage administered in different ways to women with breast cancer on their symptoms and quality of life. Int J Nurs Pract. 2014;20(4):408-17. doi: 10.1111/ijn.12128.

22. Abbaspoor Z, Mohammadkhani Shahri L. Lavender aromatherapy massages in reducing labor pain and duration of labor: a randomized controlled trial. Afr J Pharm Pharmacol. 2013;7(8):456-30. doi: 10.5897/ ajpp12.391

23. Vakilian K, Atarha M, Bekhradi R, Chaman R. Healing advantages of lavender essential oil during episiotomy recovery: a clinical trial. Complement Ther Clin Pract. 2011;17(1):50-3. doi: 10.1016/j.ctcp.2010.05.006.

24. Lane B, Cannella K, Bowen C, Copelan D, Nteff G, Barnes $\mathrm{K}$, et al. Examination of the effectiveness of peppermint aromatherapy on nausea in women post C-section. J Holist Nurs. 2012;30(2):90-104. doi: 10.1177/0898010111423419.

25. Bakhtshirin F, Abedi S, YusefiZoj P, Razmjooee D. The effect of aromatherapy massage with lavender oil on severity of primary dysmenorrhea in Arsanjan students. Iran J Nurs Midwifery Res. 2015;20(1):156-60. 
26. Lotfipur Rafsanjani SM, Vazirinejad R, Ismailzadeh S, Ansari Jaberi A, Bekhradi R, Ravari A, et al. Comparison of the efficacy of massage and aromatherapy massage with geranium on depression in postmenopausal women: a clinical trial. Zahedan J Res Med Sci. 2015;17(4):e970. doi: 10.17795/zjrms970.

27. Tillett J, Ames D. The uses of aromatherapy in women's health. J Perinat Neonatal Nurs. 2010;24(3):238-45. doi: 10.1097/JPN.0b013e3181ece75d.

28. Burns E, Blamey C. Complementary medicine. Using aromatherapy in childbirth. Nurs Times. 1994;90(9):54-60.

29. Tabatabaeichehr M, Mortazavi H. The effectiveness of aromatherapy in the management of labor pain and anxiety: a systematic review. Ethiop J Health Sci. 2020;30(3):449-58. doi: 10.4314/ejhs.v30i3.16.

30. Moeini M, Khadibi M, Bekhradi R, Mahmoudian SA, Nazari F. Effect of aromatherapy on the quality of sleep in ischemic heart disease patients hospitalized in intensive care units of heart hospitals of the Isfahan University of Medical Sciences. Iran J Nurs Midwifery Res. 2010;15(4):234-9.

31. Tournaire M, Theau-Yonneau A. Complementary and alternative approaches to pain relief during labor. Evid Based Complement Alternat Med. 2007;4(4):409-17. doi: 10.1093/ecam/nem012.

32. Jaradat NA. Medical plants utilized in Palestinian folk medicine for treatment of diabetes mellitus and cardiac diseases. J Al-Aqsa Univ Ser Nat Sci. 2005,9(1):1-28.

33. Mirzaei F, Keshtgar S, Kaviani M, Rajaeifar AR. The effect of lavender essence smelling during labor on cortisol and serotonin plasma levels and anxiety reduction in nulliparous women. J Kerman Univ Med Sci. 2009;16(3):245-54. [Persian].

34. Seraji A, Vakilian K. The comparison between the effects of aromatherapy with lavender and reathing techniques on the reduction of labor pain. Complementary Medicine Journal. 2011;1(1):34-41. [Persian].

35. Alavi N, Nemati M, Kaviani M, Tabaie MH. The effect of lavender aromatherapy on the pain intensity perception and intarapartum outcomes in primipare. Armaghane Danesh. 2010;15(1):30-7. [Persian].

36. Mohamadkhani Shahri L, Sabet Birjandi S, Mohamadkhani Shahri H. Effect of massage aromatherapy with Lavandula on the duration of first and second stage of labor in nulliparous women. Hormozgan Med J. 2013;17(2):145-54. [Persian].

37. Kaviani M, Azima S, Alavi N, Tabaei MH. The effect of lavender aromatherapy on pain perception and intrapartum outcome in primiparous women. $\mathrm{Br} \mathrm{J}$ Midwifery. 2014;22(2):125-8. doi: 10.12968/bjom.2014.22.2.125.

38. Lamadah SM, Nomani I. The effect of aromatherapy massage using lavender oil on the level of pain and anxiety during labour among primigravida women. Am J Nurs Sci. 2016;5(2):37-44.

39. Yazdkhasti M, Pirak A. The effect of aromatherapy with lavender essence on severity of labor pain and duration of labor in primiparous women. Complement Ther Clin Pract. 2016;25:81-6. doi: 10.1016/j.ctcp.2016.08.008.

40. Karo HY, Pramono N, Wahyuni S, Mashoedi ID, Latifah L. Lavender (Lavandula angustifolia) aromatherapy as an alternative treatment in reducing pain in primiparous mothers in the active first stage of labor. Belitung Nurs J. 2017,3(4):420-5. doi: 10.33546/bnj.159.

41. Yuan R, Zhang D, Yang J, Wu Z, Luo C, Han L, et al. Review of aromatherapy essential oils and their mechanism of action against migraines. Journal of Ethnopharmacology. 2021;265:113326.

42. Stevensen C. The psychophysiological effects of aromatherapy massage following cardiac surgery. Complement Ther Med. 1994;2(1):27-35. doi: 10.1016/0965-2299(94)90156-2.

43. Beesley A, Hardcastle J, Hardcastle PT, Taylor CJ. Influence of peppermint oil on absorptive and secretory processes in rat small intestine. Gut. 1996;39(2):214-9. doi: 10.1136/ gut.39.2.214.

44. de Moura Linck V, da Silva AL, Figueiró M, Luis Piato Â, Paula Herrmann A, Dupont Birck F, et al. Inhaled linaloolinduced sedation in mice. Phytomedicine. 2009;16(4):3037. doi: 10.1016/j.phymed.2008.08.001.

45. Re L, Barocci S, Sonnino S, Mencarelli A, Vivani C, Paolucci G, et al. Linalool modifies the nicotinic receptorion channel kinetics at the mouse neuromuscular junction. Pharmacol Res. 2000;42(2):177-82. doi: 10.1006/ phrs.2000.0671.

46. Adams ED, Bianchi AL. A practical approach to labor support. J Obstet Gynecol Neonatal Nurs. 2008;37(1):10615. doi: 10.1111/j.1552-6909.2007.00213.x.

47. Mirzaiinajmabadi K, Makvandi S, Mirteimoori M, Sadeghi R. An update on the effect of massage and inhalation aromatherapy with lavender on labor pain relief: a systematic review and meta-analysis. J Obstet Gynecol Cancer Res. 2018;3(1):29-37. doi: 10.21859/joqcr.3.1.29.

48. Chen SF, Wang CH, Chan PT, Chiang HW, Hu TM, Tam $\mathrm{KW}$, et al. Labour pain control by aromatherapy: a metaanalysis of randomised controlled trials. Women Birth. 2019;32(4):327-35. doi: 10.1016/j.wombi.2018.09.010.

49. Makvandi S, Mirzaiinajmabadi K, Tehranian N, Esmily H, Mirteimoori M. The effect of normal physiologic childbirth on labor pain relief: an interventional study in motherfriendly hospitals. Maedica (Bucur). 2018;13(4):286-93. doi: 10.26574/maedica.2018.13.4.286. 